\title{
Corrigendum to "Progressive breathlessness in COPD - The role of hyperinflation and its pharmacological management"' [Prim Care Resp J 2005; 14 (6): 285-293]
}

\author{
David Price $^{a, *}$, Daryl Freeman ${ }^{a}$, Alan Kaplan ${ }^{b}$, Anders Østrem $^{a}$, \\ James Reid ${ }^{c}$, Thys van der Molen ${ }^{a}$
}

${ }^{a}$ Department of General Practice and Primary Care, University of Aberdeen, Foresterhill Health Centre, Westburn Road, Aberdeen AB25 2AY, Scotland, UK

b Chairperson, Family Physician Airways Group of Canada, Richmond Hill, onflerio, Canada

c Dunedin School of Medicine, University of Otago, Dunedin. New 7 cillinal y

The autiors regret that an Exofurrea on page 291, left-hand column, third paragraph, last sentence:

The text "For example, tiotropium has been shown to reduce IC. .."

should read:

"For example, tiotropium has been shown to increase IC..."

Available online at www.sciencedirect.com

SCIENCE@Direct.

Available online at http://www.thepcrj.com

DOI of original article:10.1016/j.pcrj.2005.08.005.

* Corresponding author. Tel.: +44 01224 554588; fax: +44 01224840683.

E-mail address: d.price@abdn.ac.uk (D. Price). 